OPEN ACCESS

Edited by:

Yu Ru Kou,

National Yang-Ming University,

Taiwan

Reviewed by:

Kun-Ze Lee,

National Sun Yat-sen University,

Taiwan

Ching Jung Lai,

Tzu Chi University, Taiwan

Raphael Rodrigues Perim,

The University of Texas Health

Science Center at San Antonio,

United States

*Correspondence:

Isato Fukushi

fukushi@1998.jukuin.keio.ac.jp

Specialty section:

This article was submitted to

Respiratory Physiology,

a section of the journal

Frontiers in Physiology

Received: 12 August 2021 Accepted: 15 September 2021 Published: 08 October 2021

Citation:

Fukushi I, Takeda K, Pokorski M, Kono $Y$, Yoshizawa $M$, Hasebe $Y$, Nakao A, Mori Y, Onimaru $\mathrm{H}$ and

Okada Y (2021) Activation of Astrocytes in the Persistence of Posthypoxic Respiratory Augmentation.

Front. Physiol. 12:757731. doi: 10.3389/fphys.2021.757731

\section{Activation of Astrocytes in the Persistence of Post-hypoxic Respiratory Augmentation}

\author{
Isato Fukushi ${ }^{1,2 *}$, Kotaro Takeda ${ }^{2,3}$, Mieczyslaw Pokorski, ${ }^{4,5}$, Yosuke Kono ${ }^{2,6}$, \\ Masashi Yoshizawa ${ }^{2,6}$, Yohei Hasebe ${ }^{2,6}$, Akito Nakao $^{7}$, Yasuo Mori ${ }^{7}$, Hiroshi Onimaru ${ }^{8}$ and \\ Yasumasa Okada²
}

${ }^{1}$ Faculty of Health Sciences, Uekusa Gakuen University, Chiba, Japan, ${ }^{2}$ Clinical Research Center, Murayama Medical Center, Musashimurayama, Japan, ${ }^{3}$ Faculty of Rehabilitation, School of Healthcare, Fujita Health University, Toyoake, Japan, ${ }^{4}$ Institute of Health Sciences, University of Opole, Opole, Poland, ${ }^{5}$ Faculty of Health Sciences, The Jan Dlugosz University in Czestochowa, Czestochowa, Poland, ${ }^{6}$ Department of Pediatrics, Faculty of Medicine, University of Yamanashi, Yamanashi, Japan, ${ }^{7}$ Laboratory of Molecular Biology, Department of Synthetic Chemistry and Biological Chemistry, Graduate School of Engineering, Kyoto University, Kyoto, Japan, ${ }^{8}$ Department of Physiology, Showa University School of Medicine, Tokyo, Japan

Acute hypoxia increases ventilation. After cessation of hypoxia loading, ventilation decreases but remains above the pre-exposure baseline level for a time. However, the mechanism of this post-hypoxic persistent respiratory augmentation (PHRA), which is a short-term potentiation of breathing, has not been elucidated. We aimed to test the hypothesis that astrocytes are involved in PHRA. To this end, we investigated hypoxic ventilatory responses by whole-body plethysmography in unanesthetized adult mice. The animals breathed room air, hypoxic gas mixture $\left(7 \% \mathrm{O}_{2}, 93 \% \mathrm{~N}_{2}\right)$ for $2 \mathrm{~min}$, and again room air for $10 \mathrm{~min}$ before and after i.p. administration of low $(100 \mathrm{mg} / \mathrm{kg})$ and high $(300 \mathrm{mg} / \mathrm{kg})$ doses of arundic acid (AA), an astrocyte inhibitor. AA suppressed PHRA, with the high dose decreasing ventilation below the pre-hypoxic level. Further, we investigated the role of the astrocytic TRPA1 channel, a putative ventilatory hypoxia sensor, in PHRA using astrocyte-specific Trpa1 knockout (asTrpa $1^{-/-}$) and floxed Trpa1 (Trpa1 ${ }^{\mathrm{ff} / \mathrm{f}}$ ) mice. In both Trpa $1^{1 / 4}$ and asTrpa $1^{-/}$mice, PHRA was noticeable, indicating that the astrocyte TRPA1 channel was not directly involved in PHRA. Taken together, these results indicate that astrocytes mediate the PHRA by mechanisms other than TRPA1 channels that are engaged in hypoxia sensing.

Keywords: astrocyte, hypoxia, post-hypoxic respiratory augmentation, plasticity, short-term potentiation, respiratory control, arundic acid, TRPA1

\section{INTRODUCTION}

Acute hypoxia increases ventilation. After brief hypoxic exposure, a switchback to room air is accompanied by a ventilatory fall-off in the recovery phase, but ventilation remains above the pre-hypoxic baseline for a time. Post-hypoxic persistent respiratory augmentation (PHRA) is a form of neural plasticity, which is defined as a change in the neural control system based 
on the memory-like experience (Mitchell and Johnson, 2003). The poststimulus overshoot in ventilatory activity may even go above the stimulus level as is evident in the acute hypoxic ventilatory response (HVR) to static exercise, with the mechanism ascribed to the interaction with the cardiovascular brain control or rapid release of the volitional hypothalamic control over sustained muscle tension (Pokorski et al., 1990). Neural plasticity is essential for stabilizing respiratory control, but the underlying mechanisms are not yet well known (Eldridge and Millhorn, 1986; Dahan et al., 1995; Eldridge, 1996; Powell et al., 1998).

There are plastic interactions in relay circuits of hypoxic stimulus between peripheral chemoreceptors, among which carotid body chemoreceptors are most engaged in creating the HVR, and brain respiratory control pathways (Pamenter and Powell, 2016). The multipronged complexity of PHRA is highlighted by increased carotid chemoreceptor sensitivity due to the withdrawal of the central efferent activity component running down the sinus nerve to the carotid body (Lahiri et al., 1983). That feature has been unraveled in adaptive plasticity to chronic hypoxia but is plausibly also present in repeat acute hypoxic episodes characteristic of sleep apnea syndrome, the disease that distinctly affects brain function and increases chemoreflex sensitivity (Prabhakar, 2016).

Limited understanding of peripheral and central underliers of respiratory plasticity spurred novel lines of research, one of which is the role of transient receptor potential ankyrin 1 (TRPA1) channel. These channels participate in shaping the acute HVR (Pokorski et al., 2014). However, the channels have never been verified in carotid chemoreceptor cells and their effects on the HVR are mediated by mechanisms other than the carotid body (Pokorski et al., 2014). It has been shown that TRPA1 is localized in the chemosensitive parafacial respiratory group ( $\mathrm{pFRG} / \mathrm{RTN}$ ) astrocytes in which hypoxiainduced TRPA 1 activation facilitates exocytosis of ATP-containing vesicles (Uchiyama et al., 2020). On the basis of these findings, TRPA1 channels in astrocytes have been proposed as an oxygen sensor for respiratory control (Uchiyama et al., 2020). The proposition is in line with studies that show the role of astrocytes in brain synaptic plasticity (De Pittà et al., 2016; Schiera et al., 2020). Astrocytes are also influential for various aspects of respiratory control, including rhythm generation (Okada et al., 2012; Sheikhbahaei et al., 2018) and hypoxic and hypercapnic ventilatory responses (Gourine et al., 2010; Funk et al., 2015; Pokorski et al., 2016; Beltrán-Castillo et al., 2017; Gourine and Funk, 2017; Funk and Gourine, 2018; Sheikhbahaei et al., 2018; Guyenet et al., 2019). It has been reported that astrocytes can detect hypoxia (Tadmouri et al., 2014; Angelova et al., 2015; Fukushi et al., 2016; Onimaru et al., 2021). Therefore, we aimed to test the hypothesis that astrocytes are involved in PHRA and define the role of astrocytes, notably through TRPA1 channels, in the PHRA phenomenon. We used arundic acid (AA) as a pharmacological tool to inhibit astrocytic function in wild-type mice. We also used astrocyte Trpal knockout mice to investigate the role of astrocytic TRPA1 channels in PHRA. We found that the presence of active astrocytes is indispensable for the expression of PHRA, but their action is mediated by mechanisms other than TRPA1 channels.

\section{MATERIALS AND METHODS}

\section{Animal Welfare}

All animal experiments were performed with the approval of the Ethics Committee for Animal Experiments of the Murayama Medical Center in Tokyo and complied with the Guidelines for Care and Use of Laboratory Animals released by the National Research Council of the National Academies (8th edition, revised 2011) and with the Guiding Principles for Care and Use of Animals of the Physiological Society of Japan. A total of 34 mice (including the mice in experiments for Supplementary Figures 1, 2) were used in the experiments. All efforts were made to minimize the number of animals used.

\section{Experiments With Arundic Acid}

We used unanesthetized adult male $\mathrm{C} 57 \mathrm{BL} / 6$ mice aged $24.0 \pm 3.0$ weeks (mean $\pm \mathrm{SE}$ ). It should be the same weeks, weighing $29.6 \pm 0.7 \mathrm{~g}(n=9)$. The respiratory flow was measured noninvasively using an "open flow" whole-body plethysmograph (PLY 310, EMMS, Bordon, United Kingdom) consisting of recording (volume of $530 \mathrm{ml}$ ) and reference chambers as previously described (Oyamada et al., 2008; Pokorski et al., 2014; Fukushi et al., 2016, 2020). Briefly, the chambers were placed inside a transparent acrylic box (size $20 \times 20 \times 20 \mathrm{~cm}$ ). Each mouse was placed in the pre-calibrated recording chamber. The chamber temperature was maintained at $25^{\circ} \mathrm{C}$ throughout. The air in the recording chamber was suctioned with a constant flow generator (MV-6005VP, E.M.P-Japan, Tokyo, Japan), with a flow rate of $250 \mathrm{ml} / \mathrm{min}$. To calculate the airflow, the pressure difference between the recording and reference chambers was measured with a differential pressure transducer (TPF100, EMMS) connected to an amplifier (AIU060, Information \& Display Systems, Bordon, United Kingdom) and was bandpass filtered at $0.1-20 \mathrm{~Hz}$. We calculated tidal volume $\left(\mathrm{V}_{\mathrm{T}} ; \mu \mathrm{l} / \mathrm{g}\right.$ b.w. $)$ for each breath by integrating the airflow whose changes are proportional to those in the chamber pressure (Lundblad et al., 2002). We counted the number of breaths and obtained respiratory rate (RR; breaths $/ \mathrm{min})$. Minute ventilation $\left(\mathrm{V}_{\mathrm{E}} ; \mathrm{ml} / \mathrm{g} / \mathrm{min}\right)$ was calculated as $\mathrm{V}_{\mathrm{T}} \times \mathrm{RR}$ for each minute. The $\mathrm{V}_{\mathrm{E}}$ during hypoxia was calculated as a 2-min average and during the recovery phase as an average of the first $5 \mathrm{~min}$ (Recovery 1 ) and second 5 min (Recovery 2). The $\mathrm{O}_{2}$ concentration in the chamber was monitored with an $\mathrm{O}_{2}$ analyzer incorporating a polarographic sensor (Respina IH 26, San-ei, Tokyo, Japan) and was adjusted by controlling the mixing of $\mathrm{N}_{2}$ and air blown into the acrylic box. The pressure and $\mathrm{O}_{2}$ concentration data were simultaneously digitized at a $400 \mathrm{~Hz}$ sampling rate with an $\mathrm{A} / \mathrm{D}$ converter (PowerLab4/26) and stored in a PC with LabChart7 software. The signal processing was performed using MATLAB 2020a (MathWorks, Natick, MA).

To evaluate the HVR, mice breathed room air, then a hypoxic gas mixture $\left(7 \% \mathrm{O}_{2}, 93 \% \mathrm{~N}_{2}\right.$ for $\left.2 \mathrm{~min}\right)$, and room air again before and after i.p. administration of AA. The experimental protocol consisted of three repeats of hypoxic challenges. First, dimethyl sulfoxide (DMSO), a vehicle for AA diluted in saline, was injected and the mouse was placed into the chamber to acclimatize in room air for $60 \mathrm{~min}$. Then, after recording 
normoxic baseline data for $1 \mathrm{~min}, \mathrm{~N}_{2}$ gas was blown into the acrylic box. The chamber $\mathrm{O}_{2}$ concentration rapidly declined to $7 \%$, which was maintained for $2 \mathrm{~min}$ and followed by a switchback to room air. The measurement for the recovery continued for $10 \mathrm{~min}$. This protocol was repeated after injections of two doses of AA solubilized in a mixture of DMSO and saline $(1: 4: 5 v / v)$ at 30 -min intervals. Thus, injections were made in the following sequence (1) vehicle $-0.45 \mathrm{ml} / \mathrm{kg}$ DMSO, (2) AA - $100 \mathrm{mg} / \mathrm{kg}$, and (3) AA - $200 \mathrm{mg} / \mathrm{kg}$ (cumulative AA dose of $300 \mathrm{mg} / \mathrm{kg}$ ). Although DMSO alone can affect the brain function when the dose is high, a total dose of DMSO used in the present experiment did not exceed $2.0 \mathrm{~g} / \mathrm{kg}$, which is much below the $3.5 \mathrm{~g} / \mathrm{kg}$, a dose that starts affecting respiration (Takeda et al., 2016). The total volume of saline used in the experiment was $2.24 \mathrm{ml} / \mathrm{kg}$, which is much below the $10 \mathrm{ml} / \mathrm{kg}$ reported to affect respiration in mice (Receno et al., 2018). The dosing of AA was chosen according to previous studies using this agent in in-vivo rodents (Higashino et al., 2009; Fukushi et al., 2016, 2020). Any apparent movement and sniffing artifacts interfering with breathing patterns were discarded off-line from the recording traces during the final data elaboration. The mean values of $\mathrm{V}_{\mathrm{E}}$ were submitted to a two-factor withinsubject analysis of variance (ANOVA), with three pharmacological conditions: DMSO vehicle and the two doses of AA, and four air phases (Baseline room air, Hypoxia, Recovery 1, and Recovery 2). The same statistical tests were performed for $R R$ and $V_{T}$ as for $V_{\mathrm{E}}$. A Greenhouse-Geisser adjustment was used to correct for violations of sphericity whenever necessary. Then, to quantitatively evaluate the magnitude of PHRA, we calculated the difference in $V_{E}$ between the post-hypoxic recovery and pre-hypoxic baseline levels. This difference was divided by the difference in $\mathrm{V}_{\mathrm{E}}$ between the hypoxic loading and pre-hypoxic levels to normalize for the degree of hypoxic ventilatory augmentation. The calculation provided the parameter $\Delta \mathrm{V}_{\text {ERecovery }} /$ $\Delta \mathrm{V}_{\text {EHypoxia }}$ to compare the PHRA magnitude among three drug conditions (without AA and with low and high doses of AA) in the post-hypoxic Recovery 1 and Recovery 2 phases. Statistical differences were assessed with a paired t-test. Bonferroni correction was performed for the multiple comparisons.

\section{Experiments Using Astrocyte-Specific Trpa1 Knockout Mice}

We examined the role of astrocyte TRPA1 channels in HVR and PHRA using astrocyte-specific Trpal knockout mice $\left(\right.$ asTrpa1 $1^{-1-}$ ). To generate the asTrpa1 $1^{-1-}$, two lines of mice were crossed: a transgenic mouse GFAP-Cre (mGFAP-Cre) and a recombinant Trpal floxed (Trpa1 ${ }^{\mathrm{f} / \mathrm{f}}$ ) mouse (Gregorian et al., 2009; Zappia et al., 2017; Uchiyama et al., 2020). We conducted $7 \%$ hypoxia loading experiments in asTrpa1 $1^{-1-}$ mice (seven males and five females, aged $21.8 \pm 0.4$ weeks, weighing $25.8 \pm 1.1 \mathrm{~g}$ ) and $\operatorname{Trpal}^{\mathrm{f} / \mathrm{f}}$ mice (two males and four females, aged $22.7 \pm 1.3$ weeks, weighing $24.2 \pm 0.9 \mathrm{~g}$ ) according to the same protocol and measurement methods as outlined above for the AA experiments. The mean values of $V_{E}, V_{T}$, and $R R$ were submitted to two-way ANOVA with two TRPA1 conditions (asTrpa1 $1^{-/-}$and $\operatorname{Trpa1} 1^{\mathrm{f} / \mathrm{f}}$ ) as between-factor and with four air phases (Baseline room air, Hypoxia, Recovery 1, and Recovery 2) as within-factor. A Greenhouse-Geisser adjustment was used to correct for violations of sphericity. We calculated the $\Delta \mathrm{V}_{\text {ERecovery }} /$ $\Delta \mathrm{V}_{\text {EHypoxia }}$ to compare the PHRA magnitude between the two TRPA1 conditions (asTrpa1 $1^{-/-}$and $\operatorname{Trpa1} 1^{\mathrm{f} / \mathrm{f}}$ ) in the post-hypoxic Recovery 1 and Recovery 2 phases using the Welch test. The Bonferroni correction was used for multiple comparisons in post hoc tests. A $p<0.05$ defined statistically significant differences. The analysis was performed using SPSS 24.0 (IBM, Armonk, NY).

\section{RESULTS}

\section{Effects of Arundic Acid on HVRs}

The exemplary recordings of $\mathrm{V}_{\mathrm{E}}$ profiles in the two AA conditions vs. the control condition with no AA across the baseline room air, hypoxia, and Recovery 1 and 2 phases are shown in Figure 1. There was a significant interaction between pharmacological conditions $\times$ ventilatory phases $[F(6,42)=8.08$, $p<0.001]$. On average, AA failed to affect $V_{E}$, despite some increases in $\mathrm{RR}$ after the higher dose of $\mathrm{AA}$ in room air. While $V_{E}$ increased during hypoxia on the background of $A A$, there were differences in the post-hypoxia recovery course. In the control condition, $V_{\mathrm{E}}$ decreased from the hypoxic hyperventilation level but remained higher than the pre-hypoxic baseline level in both recovery phases. In the low-dose AA condition, $\mathrm{V}_{\mathrm{E}}$ immediately returned to the pre-hypoxic baseline level during Recovery 1 but increased again above it during Recovery 2. In the high-dose $A A$ condition, $V_{E}$ decreased significantly below the pre-hypoxic baseline level during Recovery 1 and then tended to revert to the baseline level in Recovery 2 failing to reach it. The time courses of $V_{E}, V_{T}$, and $R R$ as outlined in the example shown above are summarized in Figure 2. Figure 3A shows that the $\Delta \mathrm{V}_{\text {ERecovery }} / \Delta \mathrm{V}_{\text {EHypoxia }}$, assessing the PHRA magnitude, was significantly smaller in Recovery 1 between control (no AA) and $100 \mathrm{mg} / \mathrm{kg}$ AA $(p<0.01)$ or $300 \mathrm{mg} / \mathrm{kg} \mathrm{AA}(p<0.001)$, and between 100 and $300 \mathrm{mg} / \mathrm{kg}$ AA $(p<0.05)$. The differences between control (no AA) and $300 \mathrm{mg} / \mathrm{kg} \mathrm{AA}$ and between 100 and $300 \mathrm{mg} / \mathrm{kg}$ AA distinctly persisted in Recovery 2 (Figure 3B). Thus, blockade of astrocyte activation significantly attenuated PHRA; the effect was greatly potentiated at the higher AA dose.

\section{HVRs in asTrpa1 $1^{-/-}$Mice}

$\mathrm{V}_{\mathrm{E}}$ profiles in asTrpa1 $1^{-/-}$and Trpa1 ${ }^{\mathrm{f} / \mathrm{f}}$ mice are shown in Figures 4A,B. There was a significant main effect of the ventilatory response phases $[F(3,48)=85.011, p<0.001]$ but not between the TRPA 1 conditions $[F(1,16)=1.843, p=0.193]$. In both asTrpa1 $1^{-1-}$ and Trpa1 ${ }^{\mathrm{f} / \mathrm{f}}$ mice, $\mathrm{V}_{\mathrm{E}}$ increased during hypoxia when compared to the pre-hypoxic baseline level $(p<0.001)$ and then decreased in Recovery 1 . However, $V_{\mathrm{E}}$ stayed above the baseline level throughout the recovery phases in both asTrpa1 $1^{-/-}$and $\operatorname{Trpa1} 1^{\mathrm{f} / \mathrm{f}}$ mice. Both $\mathrm{V}_{\mathrm{T}}$ and $\mathrm{RR}$ components drove ventilatory changes throughout the hypoxic course in both asTrpa1 $1^{-1-}$ and Trpa1 ${ }^{\mathrm{f} / \mathrm{f}}$ mice (Figures 4C,D).

Although there was no significant interaction of TRPA1 conditions $\times$ ventilatory phases $[F(3,48)=2.352, p=0.084]$, we performed a between-TRPA1 comparison in each phase. 
A

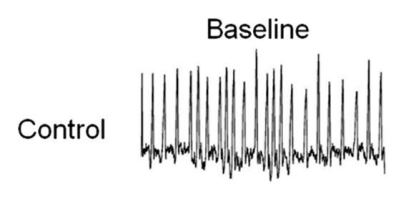

AA

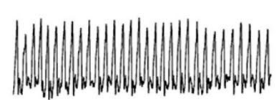

Hypoxia

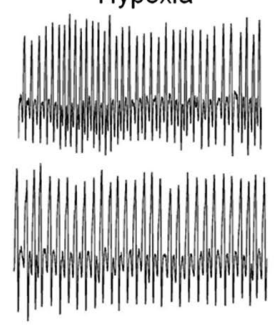

Recovery 1
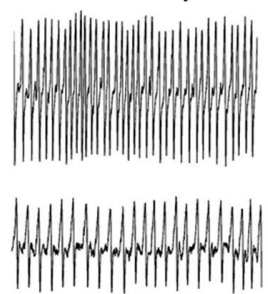

Recovery 2
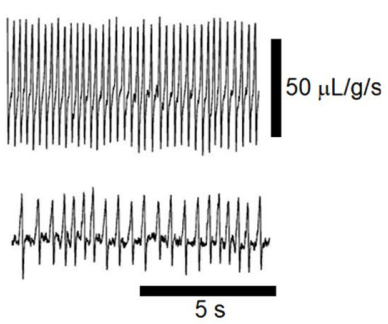

B

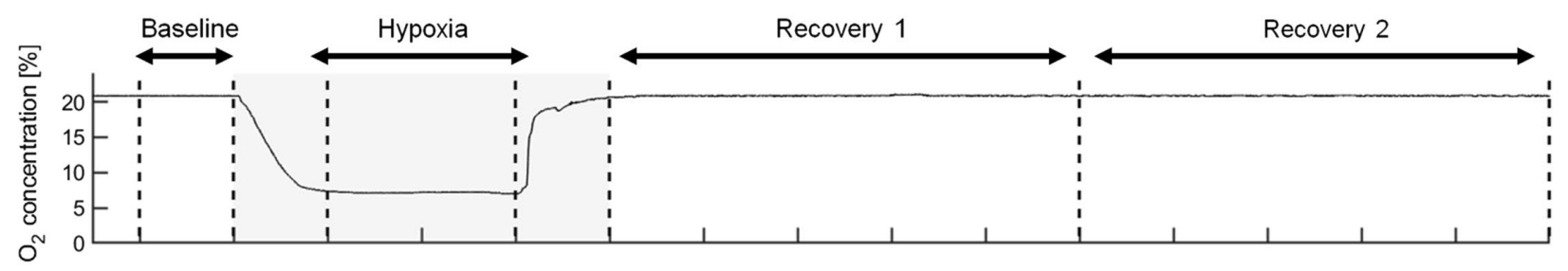

C

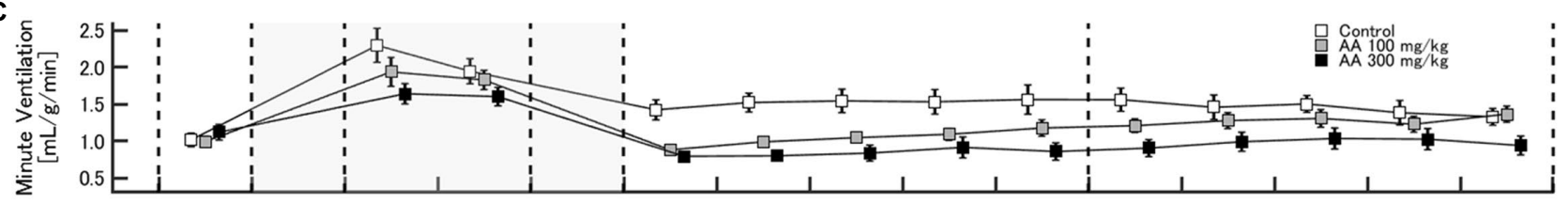

D

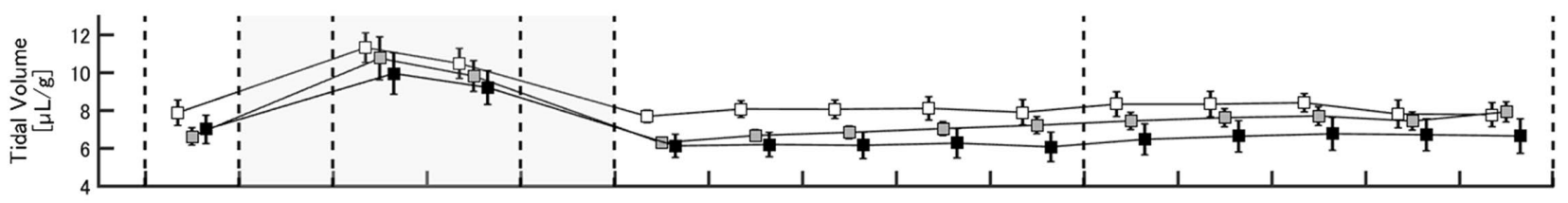

E

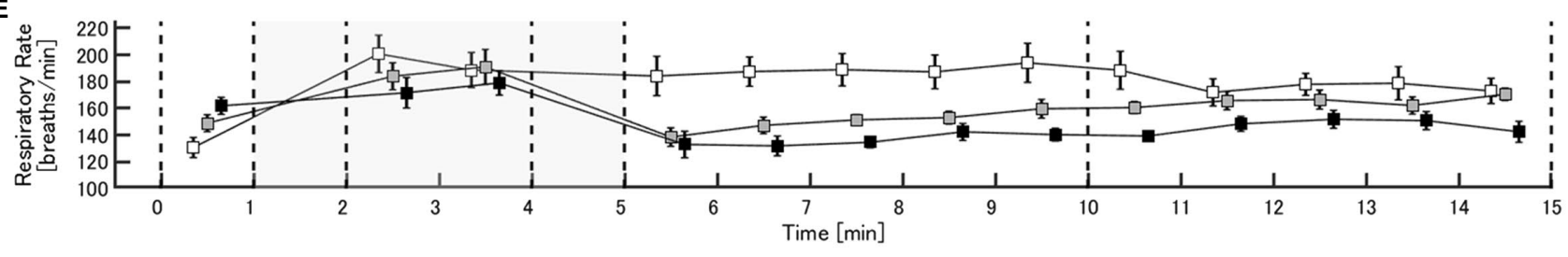

FIGURE 1 | Effects of arundic acid (AA) on hypoxic ventilatory responses (HVRs) in mice by whole-body plethysmography. (A) Representative recordings of respiratory flow (inspiration upward) in mice without and with the higher dose of AA in room air (baseline), 7\% hypoxia, Recovery 1 (first $5 \mathrm{~min}$ ), and Recovery 2 (second $5 \mathrm{~min}$ ). AA did not affect minute ventilation $\left(V_{E}\right)$ at pre-hypoxic baseline but tended to suppress the acute hypoxic hyperventilation. After the lower AA dose, $V_{E}$ immediately returned to the pre-hypoxic baseline in Recovery 1 but rebounded in Recovery 2 . After the higher $A A$ dose, $V_{E}$ decreased below the pre-hypoxic baseline in Recovery 1 and tended to revert to the baseline level in Recovery 2 failing to reach it. (B) Time-profile of chamber oxygen changes. (C-E) Time-series data for minute ventilation, tidal volume, and respiratory rate (RR), respectively, in the control (no AA) and low- and high-AA dose conditions.

$\mathrm{V}_{\mathrm{E}}$ tended to be smaller in Trpa $1^{\mathrm{f} / \mathrm{f}}$ than asTrpa1 $1^{-/-}$mice during hypoxia, but the difference was not significant $(p=0.158)$. $\mathrm{V}_{\mathrm{E}}$ became significantly smaller in asTrpa1 $1^{-/-}$mice during Recovery 1 $(p=0.034)$, but the PHRA phenomenon remained noticeable in both asTrpa1 $1^{-/-}$and Trpa1 ${ }^{\text {fff }}$ mice (Figure 4B). On average, $\Delta \mathrm{V}_{\text {ERecovery }} / \Delta \mathrm{V}_{\text {EHypoxia }}$ percentage values denoting PHRA magnitude were little different between asTrpa1 ${ }^{-/}$and $T r p a 1^{\mathrm{fff}}$ in posthypoxic Recovery 1 and 2 phases (Figures 5A,B, respectively). Although we did not conduct statistical analysis because the number of $\operatorname{Trpa}^{\mathrm{fff}}$ mice was small, there seems to be a gender difference; $\Delta V_{\text {ERecoveryl }} / \Delta V_{\text {EHypoxia }}$ values in male and female $\operatorname{Trpa1}^{\mathrm{fff}}$, and male and female asTrpa1 ${ }^{-/-}$mice were 52, 61,
67 , and $16 \%$, respectively. $\Delta \mathrm{V}_{\text {ERecovery } 2} / \Delta \mathrm{V}_{\text {EHypoxia }}$ values in these mice were $38,36,51$, and $40 \%$, respectively.

\section{DISCUSSION}

This study investigated the role of astrocytes in the PHRA, representing short-term potentiation of respiration. The findings show that astrocytes mediate PHRA. Pharmacological blockade of astrocyte activation by AA inhibited PHRA. The knockout asTrpa $1^{-/-}$mice showed less increase in ventilation in response to hypoxia than $\operatorname{Trpa1} 1^{\mathrm{fff}}$ mice. However, the magnitude of PHRA 

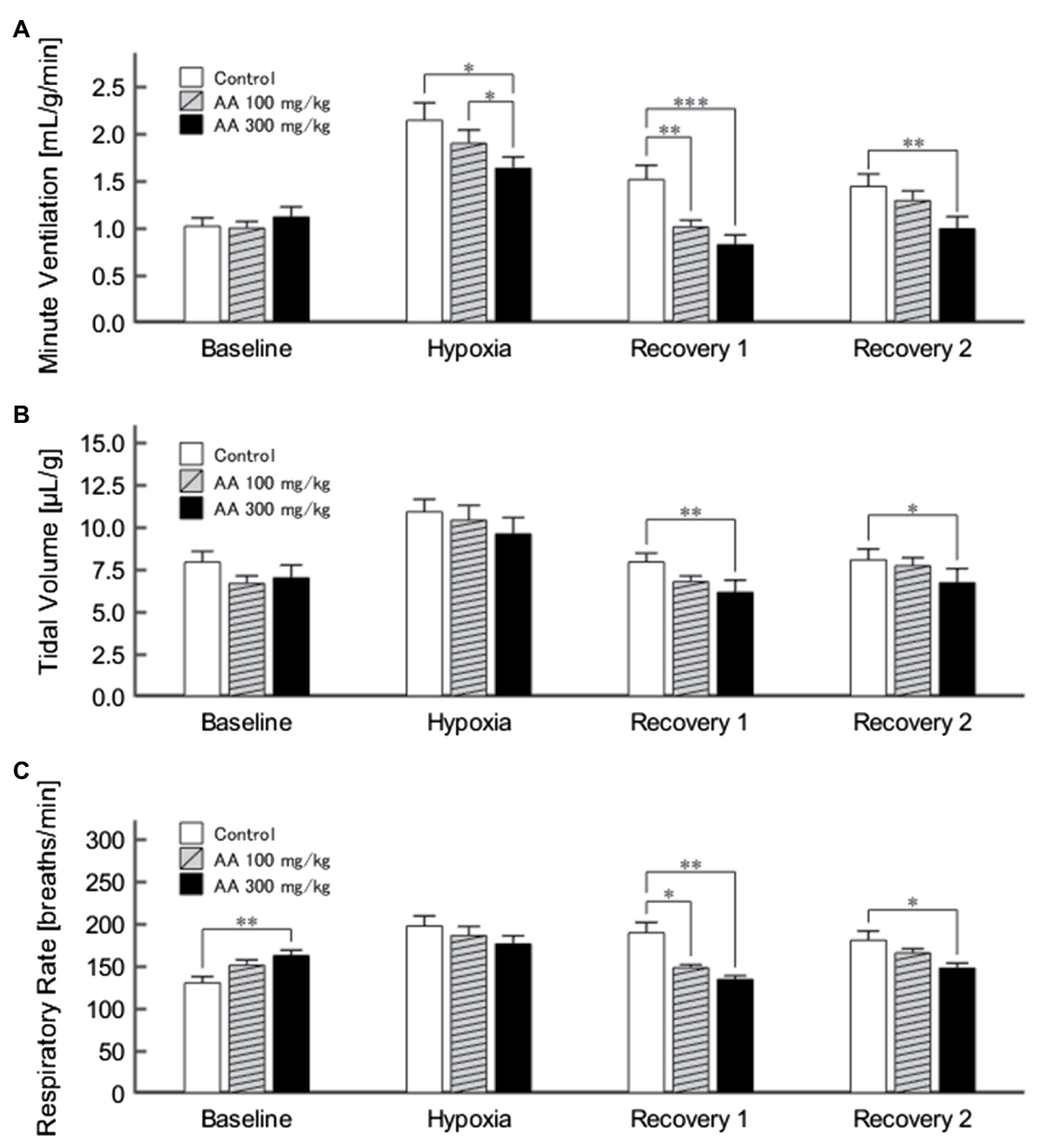

FIGURE 2 | (A) Minute ventilation $\left(V_{E}\right)$ profiles $(n=9)$ in the control (no AA) and low- and high-AA dose conditions across the successive ventilatory phases. $V_{E}$ differed significantly in the following pairwise comparisons: Control vs. AA 100 and AA 100 vs. AA 300 in hypoxia (both $p<0.05$ ); Control vs. AA 100 ( $p<0.01$ ) and Control vs. AA $300(p<0.001)$ in Recovery 1 ; and Control vs. AA $300(p<0.01)$ in Recovery 2. (B) The time-course of tidal volume $\left(V_{T}\right)$. There were main effects on $V_{T}$ of the AA condition $\left(F_{2,16}=6.596, p<0.01\right)$ and oxygen concentration $\left(F_{3,24}=89.579, \varepsilon_{\mathrm{GG}}=0.424, p<0.001\right)$, but no interaction between the two $\left(F_{6,48}=1.205\right.$, $\left.\varepsilon_{\mathrm{GG}}=0.522, p=0.329\right) . V_{\mathrm{T}}$ differed significantly in the following comparisons: Control vs. AA 300 in Recovery 1 and Control vs. AA 300 in Recovery 2 (both $p<0.01$ ). (C) Time-course of RR. There was a significant interaction between control (no AA) and two AA conditions $\times H$ VR phases $\left(F_{6,42}=12.208, p<0.001\right)$. RR differed significantly in the following comparisons: Control vs. AA 300 at baseline $(p<0.01)$; Control vs. AA $100(p<0.05)$ and Control vs. AA 300 ( $p<0.01)$ in Recovery 1 ; and Control vs. AA $300(p<0.05)$ in Recovery 2. $" p<0.05,{ }^{* *} p<0.01$, and ${ }^{* * *} p<0.001$, Bonferroni corrected.

was not attenuated in asTrpa1 ${ }^{-/-}$when compared to Trpa1 $1^{\mathrm{f} / \mathrm{f}}$ mice. Our findings demonstrate the putative role of the astrocyte TRPA1 channels in hypoxia sensing, which confirms the recent findings by Uchiyama et al. (2020). We expanded the role of astrocytes to the mediation of PHRA as well. However, TRPA1 detects mild hypoxia (13\%) more closely than severe hypoxia (7\%; Takahashi et al., 2011; Pokorski et al., 2014). This suggests that PHRA is more likely to occur under conditions of severe hypoxia. Astrocyte-related action on the short-term PHRA occurs through yet unsettled mechanisms other than TRPA1 channels. The involvement of astrocyte TRPA1 channels has been reported in the hippocampal long-term potentiation in mice (Shigetomi et al., 2013). The contribution of these channels may vary depending on the type of brain plasticity.
In the present study, we used AA, as an inhibitory modulator of astrocyte function. AA inhibits the inflammatory response of astrocytes by reducing GFAP and S100 protein synthesis, increasing the expression of the astroglial glutamate transporter GLAST and releases the glutamate receptor antagonist kynurenic acid from astrocytes (Tateishi et al., 2002; Mori et al., 2004; Asano et al., 2005; Wajima et al., 2013; Yamamura et al., 2013; Yanagisawa et al., 2015). We have previously reported that AA delays the occurrence of seizures and prevents respiratory arrest in severe hypoxia (Fukushi et al., 2020).

The present finding of counteracting the PHRA by AA indicates that astrocytes are influential in shaping respiratory neural plasticity. Hypoxia activates the carotid body, and the information is relayed via the carotid sinus nerve to the 


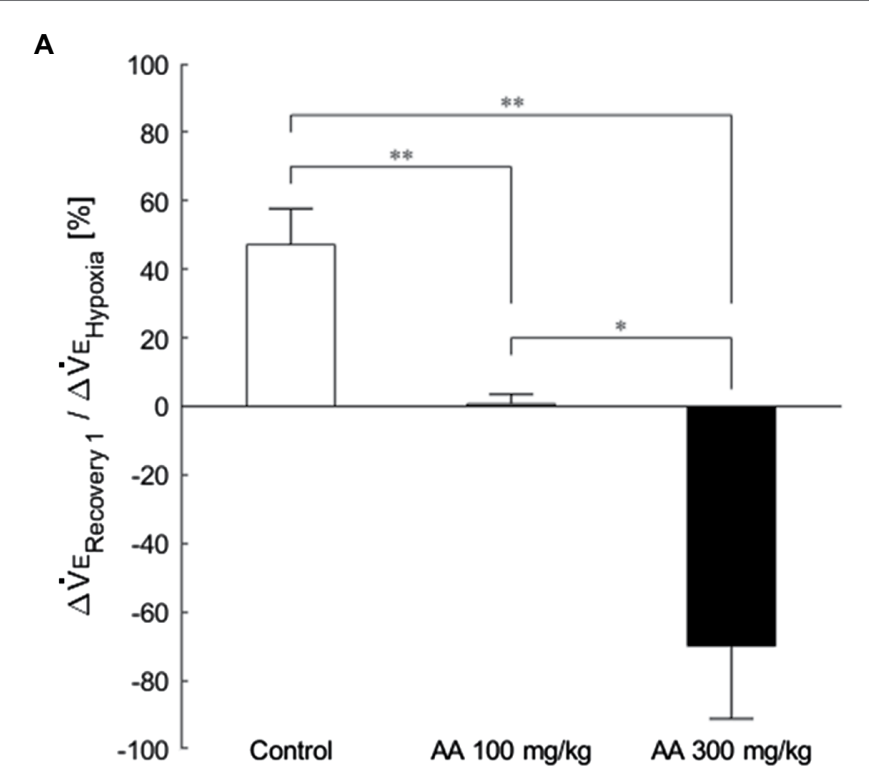

B

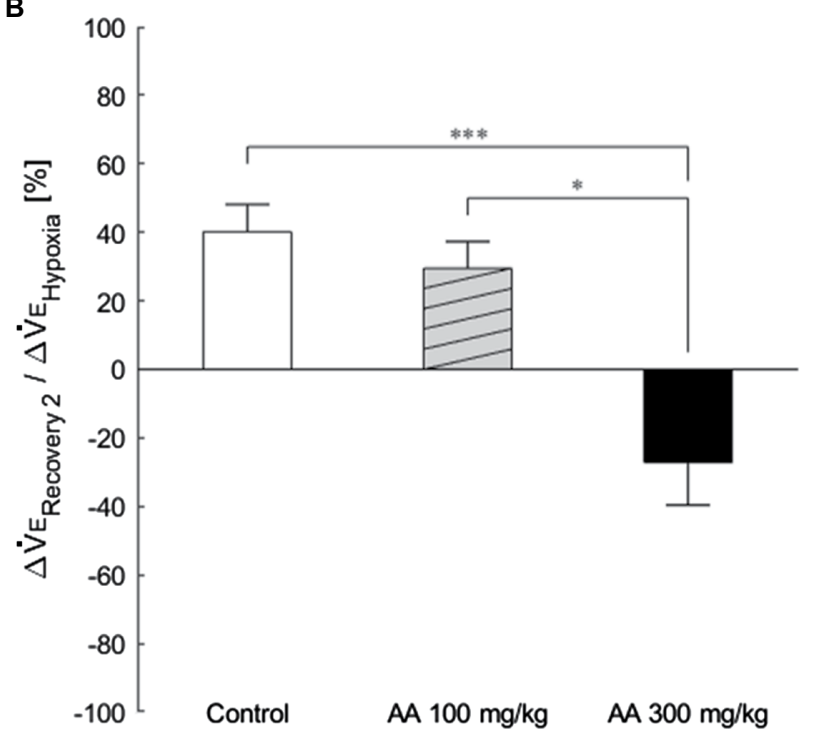

FIGURE 3 | The magnitude of effects of $A A$ on post-hypoxic persistent respiratory augmentation (PHRA) evaluated according to the formula $\triangle V_{\text {ERecovery }} / \triangle V_{\text {EHypoxia }}$ (see Materials and Methods for details). (A) Recovery 1 - PHRA differed between control (no AA) vs. AA 100, control vs. AA 300 , and AA 100 vs. AA 300 conditions. (B) Recovery 2 - PHRA differed between control (no AA) vs. AA 300. Data are means \pm SE. " $p<0.05,{ }^{* *} p<0.01$, and ${ }^{* * * *} p<0.001$, Bonferroni corrected.

medullary solitary tract nucleus, emanating to other respiratory regions in the brainstem and spinal cord (Guyenet, 2014). Astrocytes around the excited neurons are activated via neurotransmitters spilled from neurons. Once activated, they release gliotransmitters that in turn activate respiratory neurons responsible for the sustenance of respiratory potentiation. Of note, the hitherto mechanistic studies on respiratory neural plasticity have been explicitly focused on neurons but not on glial cells. The present study is the first to demonstrate that astrocytes mediate the neural plasticity of respiration.

The short-term potentiation of brain excitability, leading to the continuation of respiratory augmentation after the stimulus cessation, referred to as neural plasticity, has been previously reported (Eldridge, 1973, 1976; Tawadrous and Eldridge, 1974; Eldridge and Gill-Kumar, 1980; Wagner and Eldridge, 1991). The mechanisms of respiratory plasticity are also present in the spinal cord (Feldman et al., 2003; Mitchell and Johnson, 2003; Fuller and Mitchell, 2017). One of the most extensively investigated phenomena in this context is the phrenic long-term facilitation following acute intermittent hypoxia. Regarding the cellular mechanism of facilitation, the $\mathrm{Q}$ and $\mathrm{S}$ signaling cascades in the phrenic motor nucleus have been proposed, induced by activation of metabotropic receptors coupled to $\mathrm{Gq}$ and $\mathrm{Gs}$ proteins, respectively, interacting via crosstalk inhibition. The serotonin-dependent $\mathrm{Q}$ pathway dominates in the phrenic facilitation during mild-to-moderate hypoxia. In contrast, the $S$ pathway is serotonin-independent and dominates during severe hypoxia (Devinney et al., 2013; Fuller and Mitchell, 2017).

Recent studies have revealed an active role of astrocytes in brain plasticity related to other than respiratory functions, with a notable reference to hippocampal memory (Magistretti, 2006; Ota et al., 2013; Croft et al., 2015; Sims et al., 2015;
De Pittà et al., 2016). Astrocytes secrete synapse-modulating gliotransmitters such as glutamate, ATP, D-serine, and GABA (Jourdain et al., 2007; Henneberger et al., 2010; Takata et al., 2011; Kang et al., 2013; Shigetomi et al., 2013; Verkhratsky et al., 2016; Zorec et al., 2018; Santello et al., 2019). The regulation of postsynaptic glutamate receptors, particularly $\alpha$-amino-3-hydroxy-5-methyl-4-isoxazolepropionic acid (AMPA) receptors, is dependent on ATP released from astrocytes. The elevation in astrocytic $\mathrm{Ca}^{2+}$, occurring slowly in the order of seconds, stimulates glutamate release which activates astrocytic metabotropic glutamate receptors (Agulhon et al., 2012; Navarrete et al., 2012). The classical form of neural plasticity also depends on $\mathrm{N}$-methyl-D-aspartate (NMDA) receptors and $\mathrm{Ca}^{2+}$-dependent slow release of $\mathrm{D}$-serine from astrocytes (Henneberger et al., 2010). Further, astrocytes express a variety of receptors such as acetylcholine, ATP, GABA, and endocannabinoids (Porter and McCarthy, 1997; Haydon, 2001; Charles et al., 2003).

There are an increasing number of studies referring to the functional role of astrocytes in respiratory control other than respiratory plasticity. Astrocytes in the brainstem are sensitive to hypoxia and involved in HVR (Tadmouri et al., 2014; Angelova et al., 2015; Marina et al., 2015; Fukushi et al., 2016; Pokorski et al., 2016; Rajani et al., 2018; Uchiyama et al., 2020). Astrocytes in the ventral respiratory network, including the pre-Bötzinger complex, release ATP, which increases respiratory activity during hypoxia, putatively counteracting the depressive effects of hypoxia (Gourine et al., 2005; Marina et al., 2016a; Gourine and Funk, 2017; Funk and Gourine,

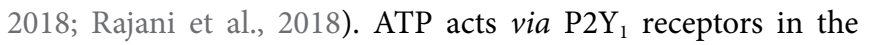
pre-Bötzinger complex to increase the respiratory burst rate with increases in intracellular $\mathrm{Ca}^{2+}$ and glutamate release (Lorier et al., 2007; Huxtable et al., 2010). Astrocytes also are strongly 
A

Baseline

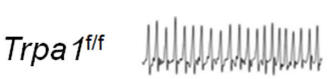

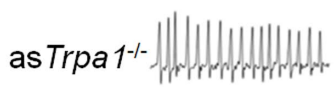

Hypoxia
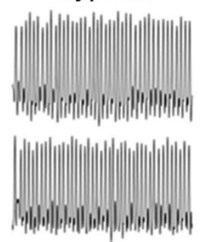

Recovery 1
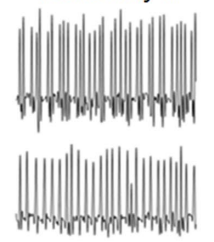

Recovery 2

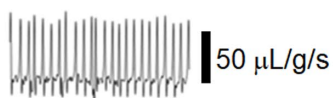

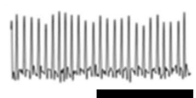

B

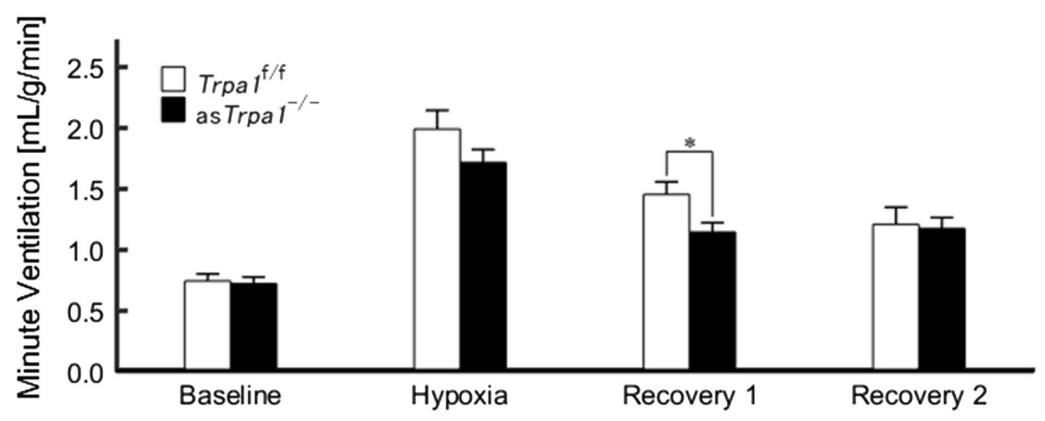

C

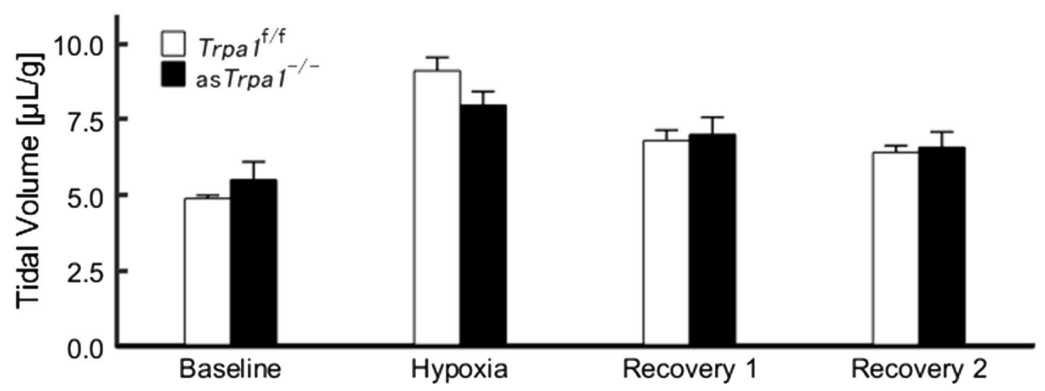

D

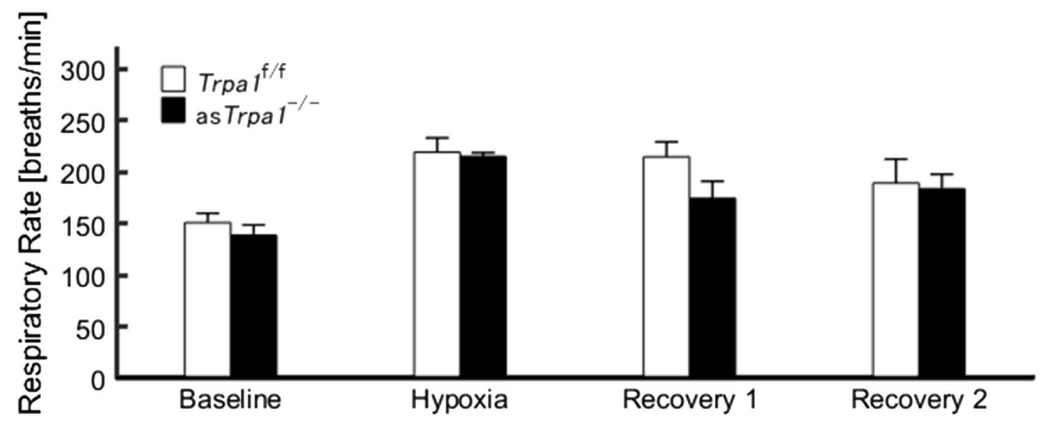

FIGURE 4 | Hypoxic ventilatory responses in asTrpa $1^{-1-}$ and Trpa $1^{\text {f/f }}$ mice. (A) Representative recordings of respiratory flow (inspiration upward) in room air (baseline), 7\% hypoxia, Recovery 1 (first $5 \mathrm{~min}$ ), and Recovery 2 (second $5 \mathrm{~min}$ ). In both asTrpa ${ }^{-/-}$and Trpa ${ }^{1 / f}$ mice, minute ventilation $\left(V_{E}\right)$ increased during hypoxia and then decreased in Recovery 1, remaining significantly elevated over the baseline level throughout both recovery phases. In Recovery $1, V_{E}$ was smaller in asTrpa1 $1^{-/-}$than Trpa $1^{\text {fff }}$ mice (B) Minute ventilation $\left(V_{E}\right)$ in Trpa $1^{\text {fff }}(n=12)$ and asTrpa $1^{-/-}(n=6)$ mice in successive ventilatory phases. Of note, $V_{E}$ was significantly smaller in asTrpa $1^{-/-}$than Trpa $1^{\text {t/f }}$ in Recovery $1(p=0.034)$. (C) Tidal volume $\left(V_{T}\right)$ in successive ventilatory phases. There was a significant interaction between transient receptor potential ankyrin 1 (TRPA1) conditions (asTrpa $1^{-/-}$and Trpa $\left.1^{1 /}\right) \times$ ventilatory response phases $\left(F_{3,48}\right.$ in asTrpa $1^{-/-}$and $\operatorname{Trpa} 1^{1 / f}$ mice $=3.318$, $\left.\varepsilon_{\mathrm{GG}}=0.658, p<0.05\right)$ but not between TRPA1 condition and $V_{T}$ in any of the ventilatory phases. Pairwise comparisons in as Trpa1 $1^{-1-}:$ Baseline vs. Hypoxia $(p<0.001)$, Baseline vs. Recovery 1 and Baseline vs. Recovery 2 (both $p<0.01$ ), and Hypoxia vs. Recovery $2(p<0.05)$ and in Trpa ${ }^{\text {tff }}$ Baseline vs. Hypoxia ( $p<0.001$ ), Baseline vs. Recovery 1, Baseline vs. Recovery 2, Hypoxia vs. Recovery 1 , and Hypoxia vs. Recovery 2 (all $p<0.01$ ). (D) RR in successive ventilatory phases. There was a significant main effect on RR of the ventilatory response phases $\left(F_{3,48}=17.967, p<0.001\right)$ but no significant interaction between RR and TRPA1 conditions $\left(F_{3,48}=1.396, p=0.08\right)$. There were no significant pairwise differences between ventilatory response phases in either as Trpa $1^{-/-}$or Trpa $1^{t / f}$. Data are means $\pm \mathrm{SE}$. " $p<0.05$; Bonferroni corrected.

involved in the central control of sympathetic activity and cardiovascular function, including systemic hypertension (Marina et al., 2016b), which are enhanced by acute and particularly repeat hypoxia episodes sensed by carotid chemoreceptors (Prabhakar et al., 2015). There is a biological plausibility that medullary astrocytes, respiratory neurons, and peripheral 
A

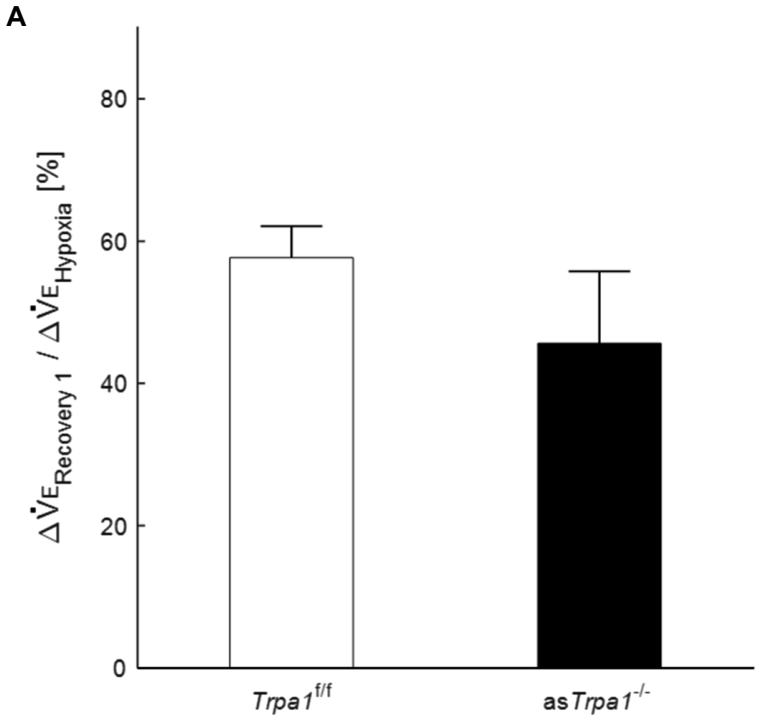

B

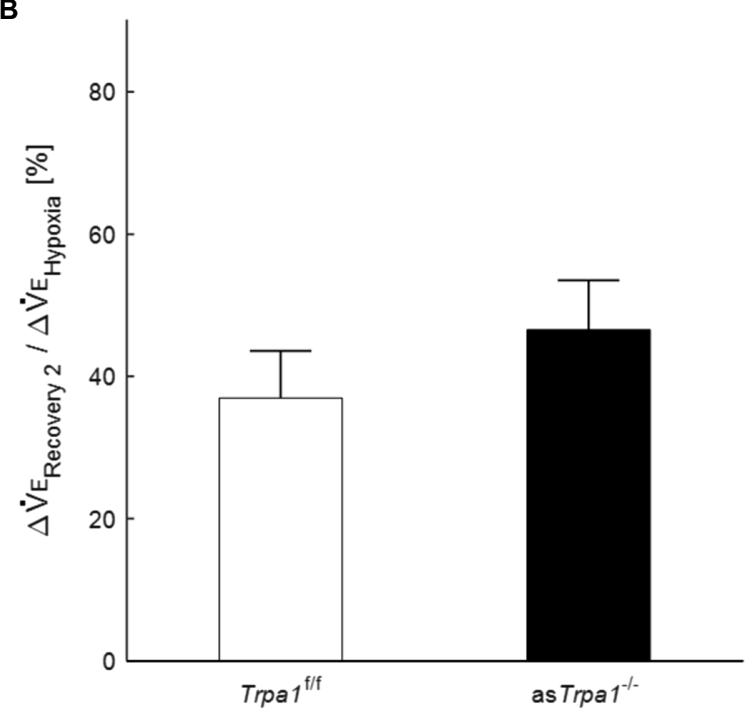

FIGURE 5 | Post-hypoxic persistent respiratory augmentation in astrocyte-specific Trpa1 knockout mice. The $\Delta \mathrm{V}_{\text {ERecovery }} / \Delta \mathrm{V}_{\text {EHypoxia }}$, denoting PHRA, were not significantly different between asTrpa $1^{-/-}$and Trpa $1^{1 / 4}$ in either Recovery 1 (A) or Recovery 2 (B). Data are means \pm SE.

chemosensing intertwine with each other in shaping PHRA. Alternative study designs are needed to further explore this issue.

In the present study, AA failed to affect $\mathrm{V}_{\mathrm{E}}$, although $\mathrm{RR}$ was increased in mice receiving a high dose of $\mathrm{AA}$ in room air. This phenomenon suggests that AA can affect breathing, i.e., inhibition of astrocyte activation may alter breathing patterns. In line with this notion, we showed that HVR was attenuated by a high dose of AA. However, AA blunted PHRA much more, suggesting that PHRA is activity-dependent plasticity.

There may be a concern over the time-dependent stability of minute ventilation on the background of a high dose of AA. Our additional investigation revealed that minute ventilation was stable over $240 \mathrm{~min}$ in this condition (Supplementary Figure 1). Likewise, another set of control investigations showed that hypoxia loadings repeated three times provide close reproducibility (Supplementary Figure 2).

One potential limitation of this study could be a lack of the animal's temperature control. In the classical "closed chamber" whole-body plethysmography, tidal volume is calculated by measuring the chamber pressure based on the combined gas law stating that the ratio of the product of gas pressure and volume to the absolute gas temperature is equal to a constant (Drorbaugh and Fenn, 1955). The chamber pressure is recorded while the chamber is sealed, and the body temperature weighs in on the result (Mayer et al., 2014; Rourke et al., 2016; Baby et al., 2018). In practice, however, the body temperature changes are so small during the hypoxic challenges of a couple of minutes that they are usually neglected for the sake of simplicity (Onodera et al., 1997). In the present study, we adopted the "open flow" plethysmography in which the chamber gas is continuously suctioned at a constant flow rate during the continuous recording. We calculated the tidal volume by integrating the airflow whose changes are proportional to those in the chamber pressure (Lundblad et al., 2002). In this case, tidal volume is expressed at ambient temperature $\left(25^{\circ} \mathrm{C}\right)$, which obviates the need for taking the animal's body temperature. Another limitation of this study was that we failed to examine metabolic rate in knock-out mice or its potential alterations by AA, which could influence respiration. Metabolic aspects require further exploration using alternative study designs.

The ultimate purpose of this research was to refer to the mechanism of post-hypoxic short-term respiratory plasticity in unanesthetized humans, which is essential to get insights into the pathophysiology of and preventive measures for periodic breathing, e.g., sleep apnea. This purpose stemmed from the studies showing that PHRA is involved in the mitigation of periodic breathing in sleep apnea (Georgopoulus et al., 1992; Mahamed and Mitchell, 2007; Mateika and Syed, 2013; Mateika and Komnenov, 2017) and heart failure (Ahmed et al., 1994); the notion supported in a computer simulation study (Eldridge, 1996). Our results showed that astrocytes, but not the astrocytic TRPA1 channel, were involved in the development of PHRA, suggesting that the TRPA1 is engaged in shaping HVR but not PHRA. The TRPA1 channel likely plays a (patho)physiological role in acute hypoxic conditions such as an attack of bronchial asthma (Shen et al., 2012). In diseases with periodic breathing such as sleep apnea, astrocytes may contribute to its prevention by exerting PHRA. Additionally, the observation that $\Delta \mathrm{V}_{\text {ERecoveryl }} /$ $\Delta \mathrm{V}_{\mathrm{EHypoxia}}$ tended to be smaller in the female asTrpa1 $1^{-/-}$mice raises the implication of a greater role of astrocytic TRPA1 in the female gender, which requires further exploration.

In conclusion, we have provided novel aspects of PHRA's role linking it to astrocyte activation and suggesting that this tandem arrangement contributes to respiratory stability and potentially might be influential in the prevention of periodic breathing. However, caution should be exercised in the translation of animal findings to human settings before further exploratory research. We conclude that astrocytes mediate the post-hypoxic 
persisting respiratory augmentation by mechanisms other than the hitherto recognized role of TRPA1 channels in hypoxia sensing.

\section{DATA AVAILABILITY STATEMENT}

The original contributions presented in the study are included in the article/Supplementary Material, further inquiries can be directed to the corresponding author.

\section{ETHICS STATEMENT}

The animal study was reviewed and approved by Ethics Committee for Animal Experiments of the Murayama Medical Center.

\section{AUTHOR CONTRIBUTIONS}

IF conceived and designed the study, performed the animal experiments, analyzed the data, and drafted the manuscript.

\section{REFERENCES}

Agulhon, C., Sun, M. Y., Murphy, T., Myers, T., Lauderdale, K., and Fiacco, T. A. (2012). Calcium signaling and gliotransmission in normal vs. reactive astrocytes. Front. Pharmacol. 3:139. doi: 10.3389/fphar.2012.00139

Ahmed, M., Serrette, C., Kryger, M. H., and Anthonisen, N. R. (1994). Ventilatory instability in patients with congestive heart failure and nocturnal Cheynestokes breathing. Sleep 17, 527-534. doi: 10.1093/sleep/17.6.527

Angelova, P. R., Kasymov, V., Christie, I., Sheikhbahaei, S., Turovsky, E., Marina, N., et al. (2015). Functional oxygen sensitivity of astrocytes. J. Neurosci. 35, 10460-10473. doi: 10.1523/JNEUROSCI.0045-15.2015

Asano, T., Mori, T., Shimoda, T., Shinagawa, R., Satoh, S., Yada, N., et al. (2005). Arundic acid (ONO-2506) ameliorates delayed ischemic brain damage by preventing astrocytic overproduction of S100B. Curr. Drug Targets CNS Neurol. Disord. 4, 127-142. doi: 10.2174/1568007053544084

Baby, S. M., Gruber, R. B., Young, A. P., MacFarlane, P. M., Teppema, L. J., and Lewis, S. J. (2018). Bilateral carotid sinus nerve transection exacerbates morphine-induced respiratory depression. Eur. J. Pharmacol. 834, 17-29. doi: $10.1016 /$ j.ejphar.2018.07.018

Beltrán-Castillo, S., Olivares, M. J., Contreras, R. A., Zúñiga, G., Llona, I., von Bernhardi, R., et al. (2017). D-serine released by astrocytes in brainstem regulates breathing response to $\mathrm{CO}_{2}$ levels. Nat. Commun. 8:838. doi: 10.1038/ s41467-017-00960-3

Charles, K. J., Deuchars, J., Davies, C. H., and Pangalos, M. N. (2003). GABAB receptor subunit expression in glia. Mol. Cell. Neurosci. 24, 214-223. doi: 10.1016/S1044-7431(03)00162-3

Croft, W., Dobson, K. L., and Bellamy, T. C. (2015). Plasticity of neuron-glial transmission: equipping glia for long-term integration of network activity. Neural Plast. 2015:765792. doi: 10.1155/2015/765792

Dahan, A., Berkenbosch, A., DeGoede, J., van den Elsen, M., Olievier, I., and van Kleef, J. (1995). Influence of hypoxic duration and post-hypoxic inspired $\mathrm{O}_{2}$ concentration on short term potentiation of breathing in humans. J. Physiol. 488, 803-813. doi: 10.1113/jphysiol.1995.sp021012

De Pittà, M., Brunel, N., and Volterra, A. (2016). Astrocytes: orchestrating synaptic plasticity? Neuroscience 323, 43-61. doi: 10.1016/j.neuroscience.2015.04.001

Devinney, M. J., Huxtable, A. G., Nichols, N. L., and Mitchell, G. S. (2013). Hypoxia-induced phrenic long-term facilitation: emergent properties. Ann. N. Y. Acad. Sci. 1279, 143-153. doi: 10.1111/nyas.12085
KT performed the statistical analysis and drafted the manuscript. MP edited and revised the manuscript. YK, MY, and YH participated in the design of the study. AN and YM provided the animals and revised the manuscript. HO supervised the experiments and revised the manuscript. YO conceived and designed the study, analyzed the data, and revised the manuscript. All authors contributed to the article and approved the submitted version.

\section{FUNDING}

This work was supported by JSPS KAKENHI (17K08559, 18K17783, 19K17386, 19K17620, 20K19368, and 20K19474) and the Japanese Physical Therapy Association (JPTA2019 and JPTA2020).

\section{SUPPLEMENTARY MATERIAL}

The Supplementary Material for this article can be found online at: https://www.frontiersin.org/articles/10.3389/fphys.2021.757731/ full\#supplementary-material

Drorbaugh, J. E., and Fenn, W. O. (1955). A barometric method for measuring ventilation in newborn infants. Pediatrics 16, 81-87.

Eldridge, F. L. (1973). Posthyperventilation breathing: different effects of active and passive hyperventilation. J. Appl. Physiol. 34, 422-430. doi: 10.1152/ jappl.1973.34.4.422

Eldridge, F. L. (1976). Central neural stimulation of respiration in unanesthetized decerebrate cats. J. Appl. Physiol. 40, 23-28. doi: 10.1152/jappl.1976.40.1.23

Eldridge, F. L. (1996). "The North Carolina respiratory model," in Bioengineering Approaches to Pulmonary Physiology and Medicine. ed. M. C. K. Khoo (Boston, MA: Springer).

Eldridge, F. L., and Gill-Kumar, P. (1980). Central neural respiratory drive and afterdischarge. Respir. Physiol. 40, 49-63. doi: 10.1016/0034-5687(80)90004-3

Eldridge, F. L., and Millhorn, D. E. (1986). "Oscillation, gating, and memory in the respiratory control system," in Handbook of Physiology, Section 3: The Respiratory System: Control of Breathing, Part 1. Vol. 2. eds. N. S. Cherniack and J. G. Widdicombe (Washington, DC: American Physiological Society), 93-114.

Feldman, J. L., Mitchell, G. S., and Nattie, E. E. (2003). Breathing: rhythmicity, plasticity, chemosensitivity. Annu. Rev. Neurosci. 26, 239-266. doi: 10.1146/ annurev.neuro.26.041002.131103

Fukushi, I., Takeda, K., Uchiyama, M., Kurita, Y., Pokorski, M., Yokota, S., et al. (2020). Blockade of astrocytic activation delays the occurrence of severe hypoxia-induced seizure and respiratory arrest in mice. J. Comp. Neurol. 528, 1257-1264. doi: 10.1002/cne.24828

Fukushi, I., Takeda, K., Yokota, S., Hasebe, Y., Sato, Y., Pokorski, M., et al. (2016). Effects of arundic acid, an astrocytic modulator, on the cerebra and respiratory functions in severe hypoxia. Respir. Physiol. Neurobiol. 226, 24-29. doi: 10.1016/j.resp.2015.11.011

Fuller, D. D., and Mitchell, G. S. (2017). Respiratory neuroplasticity - overview, significance and future directions. Exp. Neurol. 287, 144-152. doi: 10.1016/j. expneurol.2016.05.022

Funk, G. D., and Gourine, A. V. (2018). CrossTalk proposal: a central hypoxia sensor contributes to the excitatory hypoxic ventilatory response. J. Physiol. 596, 2935-2938. doi: 10.1113/JP275707

Funk, G. D., Rajani, V., Alvares, T. S., Revill, A. L., Zhang, Y., Chu, N. Y., et al. (2015). Neuroglia and their roles in central respiratory control; an overview. Comp. Biochem. Physiol. A Mol. Integr. Physiol. 186, 83-95. doi: 10.1016/j.cbpa.2015.01.010 
Georgopoulus, D., Giannouli, E., Tsara, V., Argiropoulou, P., Patakas, D., and Anthonisen, N. R. (1992). Respiratory short-term poststimulus potentiation (after-discharge) in patients with obstructive sleep apnea. Am. Rev. Respir. Dis. 146, 1250-1255. doi: 10.1164/ajrccm/146.5_Pt_1.1250

Gourine, A. V., and Funk, G. D. (2017). On the existence of a central respiratory oxygen sensor. J. Appl. Physiol. (1985) 123, 1344-1349. doi: 10.1152/ japplphysiol.00194.2017

Gourine, A. V., Kasymov, V., Marina, N., Tang, F., Figueiredo, M. F., Lane, S., et al. (2010). Astrocytes control breathing through $\mathrm{pH}$-dependent release of ATP. Science 329, 571-575. doi: 10.1126/science.1190721

Gourine, A. V., Llaudet, E., Dale, N., and Spyer, K. M. (2005). Release of ATP in the ventral medulla during hypoxia in rats: role in hypoxic ventilatory response. J. Neurosci. 25, 1211-1218. doi: 10.1523/JNEUROSCI.3763-04.2005

Gregorian, C., Nakashima, J., Le Belle, J., Ohab, J., Kim, R., Liu, A., et al. (2009). Pten deletion in adult neural stem/progenitor cells enhances constitutive neurogenesis. J. Neurosci. 29, 1874-1886. doi: 10.1523/JNEUROSCI.3095-08.2009

Guyenet, P. G. (2014). Regulation of breathing and autonomic outflows by chemoreceptors. Comp. Physiol. 4, 1511-1562. doi: 10.1002/cphy.c140004

Guyenet, P. G., Stornetta, R. L., Souza, G. M. P. R., Abbott, S. B. G., Shi, Y., and Bayliss, D. A. (2019). The retrotrapezoid nucleus: central chemoreceptor and regulator of breathing automaticity. Trends Neurosci. 42, 807-824. doi: 10.1016/j.tins.2019.09.002

Haydon, P. G. (2001). GLIA: listening and talking to the synapse. Nat. Rev. Neurosci. 2, 185-193. doi: 10.1038/35058528

Henneberger, C., Papouin, T., Oliet, S. H., and Rusakov, D. A. (2010). Longterm potentiation depends on release of D-serine from astrocytes. Nature 463, 232-236. doi: 10.1038/nature08673

Higashino, H., Niwa, A., Satou, T., Ohta, Y., Hashimoto, S., Tabuchi, M., et al. (2009). Immunohistochemical analysis of brain lesions using S100B and glial fibrillary acidic protein antibodies in arundic acid- (ONO-2506) treated stroke-prone spontaneously hypertensive rats. J. Neural Transm. 116, 1209-1219. doi: $10.1007 /$ s00702-009-0278-x

Huxtable, A. G., Zwicker, J. D., Alvares, T. S., Ruangkittisakul, A., Fang, X., Hahn, L. B., et al. (2010). Glia contribute to the purinergic modulation of inspiratory rhythm-generating networks. J. Neurosci. 30, 3947-3958. doi: 10.1523/JNEUROSCI.6027-09.2010

Jourdain, P., Bergersen, L. H., Bhaukaurally, K., Bezzi, P., Santello, M., Domercq, M., et al. (2007). Glutamate exocytosis from astrocytes controls synaptic strength. Nat. Neurosci. 10, 331-339. doi: 10.1038/nn1849

Kang, N., Peng, H., Yu, Y., Stanton, P. K., Guilarte, T. R., and Kang, J. (2013). Astrocytes release D-serine by a large vesicle. Neuroscience 240, 243-257. doi: 10.1016/j.neuroscience.2013.02.029

Lahiri, S., Smatresk, N., Pokorski, M., Barnard, P., and Mokashi, A. (1983). Efferent inhibition of carotid body chemoreception in chronically hypoxic cats. Am. J. Phys. 245, R678-R683. doi: 10.1152/ajpregu.1983.245.5.R678

Lorier, A. R., Huxtable, A. G., Robinson, D. M., Lipski, J., Housley, G. D., and Funk, G. D. (2007). P2Y1 receptor modulation of the pre-Bötzinger complex inspiratory rhythm generating network in vitro. J. Neurosci. 27, 993-1005. doi: 10.1523/JNEUROSCI.3948-06.2007

Lundblad, L. K., Irvin, C. G., Adler, A., and Bates, J. H. (2002). A reevaluation of the validity of unrestrained plethysmography in mice. J. Appl. Physiol. 93, 1198-1207. doi: 10.1152/japplphysiol.00080.2002

Magistretti, P. J. (2006). Neuron-glia metabolic coupling and plasticity. J. Exp. Biol. 209, 2304-2311. doi: 10.1242/jeb.02208

Mahamed, S., and Mitchell, G. S. (2007). Is there a link between intermittent hypoxia-induced respiratory plasticity and obstructive sleep apnoea? Exp. Physiol. 92, 27-37. doi: 10.1113/expphysiol.2006.033720

Marina, N., Ang, R., Machhada, A., Kasymov, V., Karagiannis, A., Hosford, P. S., et al. (2015). Brainstem hypoxia contributes to the development of hypertension in the spontaneously hypertensive rat. Hypertension 65, 775-783. doi: 10.1161/ HYPERTENSIONAHA.114.04683

Marina, N., Kasymov, V., Ackland, G. L., Kasparov, S., and Gourine, A. V. (2016a). Astrocytes and brain hypoxia. Adv. Exp. Med. Biol. 903, 201-207. doi: 10.1007/978-1-4899-7678-9_14

Marina, N., Teschemacher, A. G., Kasparov, S., and Gourine, A. V. (2016b). Glia, sympathetic activity and cardiovascular disease. Exp. Physiol. 101, 565-576. doi: 10.1113/EP085713

Mateika, J. H., and Komnenov, D. (2017). Intermittent hypoxia initiated plasticity in humans: a multipronged therapeutic approach to treat sleep apnea and overlapping co-morbidities. Exp. Neurol. 287, 113-129. doi: 10.1016/j. expneurol.2016.05.011

Mateika, J. H., and Syed, Z. (2013). Intermittent hypoxia, respiratory plasticity and sleep apnea in humans: present knowledge and future investigations. Respir. Physiol. Neurobiol. 188, 289-300. doi: 10.1016/j.resp.2013.04.010

Mayer, C. A., Di Fiore, J. M., Martin, R. J., and Macfarlane, P. M. (2014). Vulnerability of neonatal respiratory neural control to sustained hypoxia during a uniquely sensitive window of development. J. Appl. Physiol. 116, 514-521. doi: 10.1152/japplphysiol.00976.2013

Mitchell, G. S., and Johnson, S. M. (2003). Neuroplasticity in respiratory motor control. J. Appl. Physiol. 94, 358-374. doi: 10.1152/japplphysiol.00523.2002

Mori, T., Tateishi, N., Kagamiishi, Y., Shimoda, T., Satoh, S., Ono, S., et al. (2004). Attenuation of a delayed increase in the extracellular glutamate level in the peri-infarct area following focal cerebral ischemia by a novel agent ONO-2506. Neurochem. Int. 45, 381-387. doi: 10.1016/j.neuint.2003.06.001

Navarrete, M., Perea, G., Fernandez de Sevilla, D., Gómez-Gonzalo, M., Núñez, A., Martín, E. D., et al. (2012). Astrocytes mediate in vivo cholinergic-induced synaptic plasticity. PLoS Biol. 10:e1001259. doi: 10.1371/journal.pbio.1001259

Okada, Y., Sasaki, T., Oku, Y., Takahashi, N., Seki, M., Ujita, S., et al. (2012). Preinspiratory calcium rise in putative pre-Bötzinger complex astrocytes. J. Physiol. 590, 4933-4944. doi: 10.1113/jphysiol.2012.231464

Onimaru, H., Yazawa, I., Takeda, K., Fukushi, I., and Okada, Y. (2021). Calcium imaging analysis of cellular responses to hypercapnia and hypoxia in the NTS of newborn rat brainstem preparation. Front. Physiol. 12:645904. doi: 10.3389/fphys.2021.645904

Onodera, M., Kuwaki, T., Kumada, M., and Masuda, Y. (1997). Determination of ventilatory volume in mice by whole body plethysmography. Jpn. J. Physiol. 47, 317-326. doi: 10.2170/jjphysiol.47.317

Ota, Y., Zanetti, A. T., and Hallock, R. M. (2013). The role of astrocytes in the regulation of synaptic plasticity and memory formation. Neural Plast. 2013:185463. doi: $10.1155 / 2013 / 185463$

Oyamada, Y., Murai, M., Harada, N., Ishizaka, A., and Okada, Y. (2008). Agedependent involvement of ATP-sensitive potassium channel Kir6.2 in hypoxic ventilatory depression of mouse. Respir. Physiol. Neurobiol. 162, 80-84. doi: 10.1016/j.resp.2008.04.003

Pamenter, M. E., and Powell, F. L. (2016). Time domains of the hypoxic ventilatory response and their molecular basis. Compr. Physiol. 6, 1345-1385. doi: 10.1002/cphy.c150026

Pokorski, M., Masuda, A., Paulev, P. E., Sakakibara, Y., Ahn, B., Takaishi, S., et al. (1990). Ventilatory and cardiovascular responses to hypoxic and hyperoxic static handgrip exercise in man. Respir. Physiol. 81, 189-202. doi: 10.1016/0034-5687(90)90045-Z

Pokorski, M., Takeda, K., and Okada, Y. (2016). Oxygen sensing mechanisms: a physiological penumbra. Adv. Exp. Med. Biol. 952, 1-8. doi: 10.1007/5584_2016_67

Pokorski, M., Takeda, K., Sato, Y., and Okada, Y. (2014). The hypoxic ventilatory response and TRPAl antagonism in conscious mice. Acta Physiol. 210, 928-938. doi: 10.1111/apha.12202

Porter, J. T., and McCarthy, K. D. (1997). Astrocytic neurotransmitter receptors in situ and in vivo. Prog. Neurobiol. 51, 439-455. doi: 10.1016/ S0301-0082(96)00068-8

Powell, F. L., Milsom, W. K., and Mitchell, G. S. (1998). Time domains of the hypoxic ventilatory response. Respir. Physiol. 112, 123-134. doi: 10.1016/ S0034-5687(98)00026-7

Prabhakar, N. R. (2016). Carotid body chemoreflex: a driver of autonomic abnormalities in sleep apnoea. Exp. Physiol. 101, 975-985. doi: 10.1113/ EP085624

Prabhakar, N. R., Peng, Y. J., Kumar, G. K., and Nanduri, J. (2015). Peripheral chemoreception and arterial pressure responses to intermittent hypoxia. Comp. Physiol. 5, 561-577. doi: 10.1002/cphy.c140039

Rajani, V., Zhang, Y., Jalubula, V., Rancic, V., SheikhBahaei, S., Zwicker, J. D., et al. (2018). Release of ATP by pre-Bötzinger complex astrocytes contributes to the hypoxic ventilatory response via a $\mathrm{Ca}^{2+}$-dependent $\mathrm{P} 2 \mathrm{Y} 1$ receptor mechanism. J. Physiol. 596, 3245-3269. doi: 10.1113/JP274727

Receno, C. N., Glausen, T. G., and DeRuisseau, L. R. (2018). Saline as a vehicle control does not alter ventilation in male CD-1 mice. Physiol. Rep. 6:e13702. doi: 10.14814/phy2.13702

Rourke, K. S., Mayer, C. A., and MacFarlane, P. M. (2016). A critical postnatal period of heightened vulnerability to lipopolysaccharide. Respir. Physiol. Neurobiol. 232, 26-34. doi: 10.1016/j.resp.2016.06.003 
Santello, M., Toni, N., and Volterra, A. (2019). Astrocyte function from information processing to cognition and cognitive impairment. Nat. Neurosci. 22, 154-166. doi: 10.1038/s41593-018-0325-8

Schiera, G., Di Liegro, C. M., and Di Liegro, I. (2020). Cell-to-cell communication in learning and memory: from neuro- and glio-transmission to information exchange mediated by extracellular vesicles. Int. J. Mol. Sci. 21:266. doi: 10.3390/ijms21010266

Sheikhbahaei, S., Turovsky, E. A., Hosford, P. S., Hadjihambi, A., Theparambil, S. M., Liu, B., et al. (2018). Astrocytes modulate brainstem respiratory rhythmgenerating circuits and determine exercise capacity. Nat. Commun. 9:370. doi: 10.1038/s41467-017-02723-6

Shen, M. Y., Luo, Y. L., Yang, C. H., Ruan, T., and Lai, C. J. (2012). Hypersensitivity of lung vagal $\mathrm{C}$ fibers induced by acute intermittent hypoxia in rats: role of reactive oxygen species and TRPA1. Am. J. Phys. Regul. Integr. Comp. Phys. 303, R1175-R1185. doi: 10.1152/ajpregu.00227.2012

Shigetomi, E., Jackson-Weaver, O., Huckstepp, R. T., O’Dell, T. J., and Khakh, B. S. (2013). TRPA1 channels are regulators of astrocyte basal calcium levels and long-term potentiation via constitutive D-serine release. J. Neurosci. 33, 10143-10153. doi: 10.1523/JNEUROSCI.5779-12.2013

Sims, R. E., Butcher, J. B., Parri, H. R., and Glazewski, S. (2015). Astrocyte and neuronal plasticity in the somatosensory system. Neural Plast. 2015:732014. doi: $10.1155 / 2015 / 732014$

Tadmouri, A., Champagnat, J., and Morin-Surun, M. P. (2014). Activation of microglia and astrocytes in the nucleus tractus solitarius during ventilatory acclimatization to $10 \%$ hypoxia in unanesthetized mice. J. Neurosci. Res. 92, 627-633. doi: 10.1002/jnr.23336

Takahashi, N., Kuwaki, T., Kiyonaka, S., Numata, T., Kozai, D., Mizuno, Y., et al. (2011). TRPA1 underlies a sensing mechanism for $\mathrm{O}_{2}$. Nat. Chem. Biol. 7, 701-711. doi: 10.1038/nchembio.640

Takata, N., Mishima, T., Hisatsune, C., Nagai, T., Ebisui, E., Mikoshiba, K., et al. (2011). Astrocyte calcium signaling transforms cholinergic modulation to cortical plasticity in vivo. J. Neurosci. 31, 18155-18165. doi: 10.1523/ JNEUROSCI.5289-11.2011

Takeda, K., Pokorski, M., Sato, Y., Oyamada, Y., and Okada, Y. (2016). Respiratory toxicity of dimethyl sulfoxide. Adv. Exp. Med. Biol. 885, 89-96. doi: 10.1007/5584_2015_187

Tateishi, N., Mori, T., Kagamiishi, Y., Satoh, S., Katsube, N., Morikawa, E., et al. (2002). Astrocytic activation and delayed infarct expansion after permanent focal ischemia in rats. Part II: suppression of astrocytic activation by a novel agent (R)-(-)-2-propyloctanoic acid (ONO-2506) leads to mitigation of delayed infarct expansion and early improvement of neurologic deficits. J. Cereb. Blood Flow Metab. 22, 723-734. doi: 10.1097/00004647-200206000-00011

Tawadrous, F. D., and Eldridge, F. L. (1974). Posthyperventilation breathing patterns after active hyperventilation in man. J. Appl. Physiol. 37, 353-356. doi: $10.1152 /$ jappl.1974.37.3.353
Uchiyama, M., Nakao, A., Kurita, Y., Fukushi, I., Takeda, K., Numata, T., et al. (2020). $\mathrm{O}_{2}$-dependent protein internalization underlies astrocytic sensing of acute hypoxia by restricting multimodal TRPA1 channel responses. Curr. Biol. 30, 3378.e7-3396.e7. doi: 10.1016/j.cub.2020.06.047

Verkhratsky, A., Matteoli, M., Parpura, V., Mothet, J. P., and Zorec, R. (2016). Astrocytes as secretory cells of the central nervous system: idiosyncrasies of vesicular secretion. EMBO J. 35, 239-257. doi: 10.15252/embj.201592705

Wagner, P. G., and Eldridge, F. L. (1991). Development of short-term potentiation of respiration. Respir. Physiol. 83, 129-139. doi: 10.1016/0034-5687(91)90098-4

Wajima, D., Nakagawa, I., Nakase, H., and Yonezawa, T. (2013). Neuroprotective effect of suppression of astrocytic activation by arundic acid on brain injuries in rats with acute subdural hematomas. Brain Res. 1519, 127-135. doi: 10.1016/j.brainres.2013.05.002

Yamamura, S., Hoshikawa, M., Dai, K., Saito, H., Suzuki, N., Niwa, O., et al. (2013). ONO-2506 inhibits spike-wave discharges in a genetic animal model without affecting traditional convulsive tests via gliotransmission regulation. Br. J. Pharmacol. 168, 1088-1100. doi: 10.1111/j.1476-5381.2012.02132.x

Yanagisawa, M., Aida, T., Takeda, T., Namekata, K., Harada, T., Shinagawa, R., et al. (2015). Arundic acid attenuates retinal ganglion cell death by increasing glutamate/aspartate transporter expression in a model of normal tension glaucoma. Cell Death Dis. 6:e1693. doi: 10.1038/cddis.2015.45

Zappia, K. J., O'Hara, C. L., Moehring, F., Kwan, K. Y., and Stucky, C. L. (2017). Sensory neuron-specific deletion of TRPA1 results in mechanical cutaneous sensory deficits. eNeuro 4:ENEURO.0069-16.2017. doi: 10.1523/ ENEURO.0069-16.2017

Zorec, R., Parpura, V., and Verkhratsky, A. (2018). Astroglial vesicular network: evolutionary trends, physiology and pathophysiology. Acta Physiol. 222:e12915. doi: 10.1111/apha.12915

Conflict of Interest: The authors declare that the research was conducted in the absence of any commercial or financial relationships that could be construed as a potential conflict of interest.

Publisher's Note: All claims expressed in this article are solely those of the authors and do not necessarily represent those of their affiliated organizations, or those of the publisher, the editors and the reviewers. Any product that may be evaluated in this article, or claim that may be made by its manufacturer, is not guaranteed or endorsed by the publisher.

Copyright (c) 2021 Fukushi, Takeda, Pokorski, Kono, Yoshizawa, Hasebe, Nakao, Mori, Onimaru and Okada. This is an open-access article distributed under the terms of the Creative Commons Attribution License (CC BY). The use, distribution or reproduction in other forums is permitted, provided the original author(s) and the copyright owner(s) are credited and that the original publication in this journal is cited, in accordance with accepted academic practice. No use, distribution or reproduction is permitted which does not comply with these terms. 